\title{
pRNFL as a marker of disability worsening in the medium/long term in patients with MS
}

Christian Cordano, MD, PhD, Bardia Nourbakhsh, MD, MAS, Michael Devereux, BS, Vincent Damotte, PhD, Daniel Bennett, BS, Stephen L. Hauser, MD, Bruce A. C. Cree, MD, PhD, MAS, Jeffrey M. Gelfand, MD, MAS, and Ari J. Green, MD, MCR
MS is an inflammatory and neurodegenerative disease of the CNS (including the retina) that leads to progressive neurologic disability. Disability correlates with the degree of axonal pathology in the disease. ${ }^{1,2}$ The clinical course of MS is unpredictable, making the search for biomarkers associated with enhanced risk of disease progression a major unmet need. Spectral domain optical coherence tomography (SD-OCT) is a potential predictor of disability worsening up to 5 years of follow-up after a single evaluation of the peripapillary retinal nerve fiber layer $(\mathrm{pRNFL}){ }^{3}$ Time domain OCT (TD-OCT) is an older technology, characterized by lower axial resolution and slower acquisition speed (400 axial scans per second) resulting in lower resolution images and more frequent motion artifacts compared with SD-OCT. ${ }^{4}$ TD-OCT was used over 10 years ago to assess retinal neurodegeneration in patients with MS but only now has enough time passed to assess its actual predictive potential for clinical progression.

To investigate the capacity of TD-OCT measures to predict disability worsening in patients with MS, we performed a retrospective evaluation of 305 patients with MS (228 relapsingremitting, 29 secondary progressive, 32 clinically isolated syndrome, 10 primary progressive MS according to $2005 \mathrm{McD}$ onald criteria, 5 and 6 with MS but unclear disease course) who had undergone Stratus TD-OCT (Carl Zeiss Meditec AG, Jena, Germany) from January 2006 to December 2008, collecting the values of the pRNFL and macular volume (MV). The Committee on Human Research at UCSF approved the study. All participants provided written informed consent. The baseline cohort characteristics are presented in the table. All patients had at least 1 measurement of the Expanded Disability Status Scale (EDSS) during the subsequent follow-up period. In our analyses, we used the most recent available EDSS. The median follow-up duration from the time of OCT to the most recent EDSS evaluation was 7.9 years (interquartile range $6.4-8.9$ years, range $0.04-9.5$ years); $91 \%$ of the cohort had $>5$ years of follow-up. The association between the baseline pRNFL and the subsequent EDSS was investigated using multivariable linear regression, adjusted for age and sex, taking into account the correlation of pRNFL thickness in the patient's 2 eyes (figure). For each $1-\mu \mathrm{m}$ decrease in the pRNFL, there was a 0.024 increase in EDSS (95\% CI: $0.011-0.037 ; p<0.001$ ). In a sensitivity analysis, the results were similar (0.022 increase in the EDSS, 95\% CI 0.035-0.01, $p=0.001)$ when analyzing only patients with $>5$ years of follow-up. A model adjusted for the presence of previous episodes of optic neuritis yielded similar results (a 1- $\mu \mathrm{m}$ decrease in the RNFL was associated with a 0.024 increase in the EDSS; $p<0.001$ ). There was no association with MV. The lack of consistent association of MV with disability worsening has previously been reported ${ }^{3}$ and may relate to the lack of segmentation from whole macular thickness where some layers increase volume and others lose volume during the course of disease. In addition, TD-OCT had poorer reproducibility for volume scans because of the low speed of image acquisition. These results show that TD-OCT and a single evaluation of pRNFL atrophy is

\author{
Correspondence \\ Dr. Green
}

agreen@ucsf.edu 
Table Demographic and baseline characteristics and the follow-up data of the study population (number of patients $=305$ )

\begin{tabular}{|c|c|}
\hline Female & 65.7 \\
\hline Average age (SD), y & $42.7(11.8)$ \\
\hline Average disease duration in years (SD) & $10(9.2)$ \\
\hline Average most recent EDSS (SD) & $2.9(1.9)$ \\
\hline Average days from OCT to EDSS (SD) & $2,696.4(655.0)$ \\
\hline Median years from OCT to EDSS (IQR, range) & $\begin{array}{l}7.9(6.4-8.9,0.04 \text { to } \\
9.5)\end{array}$ \\
\hline Average RNFL thickness (SD) & $88.9(15.2)$ \\
\hline Average ON-positive RNFL (SD) $(N=193)^{a}$ & $82(16.4)$ \\
\hline Average ON-negative RNFL (SD) $(\mathrm{N}=410)^{\mathrm{a}}$ & $91.9(13.5)$ \\
\hline$\%$ of patients using DMT at OCT visit & 68.7 \\
\hline $\begin{array}{l}\text { Average duration of DMT use at EDSS visit in } \\
\text { years (SD) }\end{array}$ & $10.3(5.3)$ \\
\hline \multicolumn{2}{|c|}{$\begin{array}{l}\text { Abbreviations: DMT = disease-modifying therapy; EDSS = Expanded Dis- } \\
\text { ability Status Scale; IQR = interquartile range; ON = optic neuritis; RNFL = } \\
\text { retinal nerve fiber layer. } \\
\text { a Seven eyes were excluded from the analysis because of poor quality (total } \\
\text { number of eyes }=603 \text { ). }\end{array}$} \\
\hline
\end{tabular}

useful in predicting disability up to 6-9 years later in MSsignificantly longer than has been previously reported. A limitation of the study is the absence of the baseline EDSS in the entire cohort, which limited our ability to consider its influence as a confounder in the estimate of association between the baseline RNFL and subsequent EDSS. Recent meta-analyses show that the mean RNFL loss in a population of patients with optic neuritis is similar between TD-OCT and SD-OCT. ${ }^{6,7}$ However, despite the similarity in means at an

Figure Association of baseline RNFL with EDSS at the end of the follow-up period

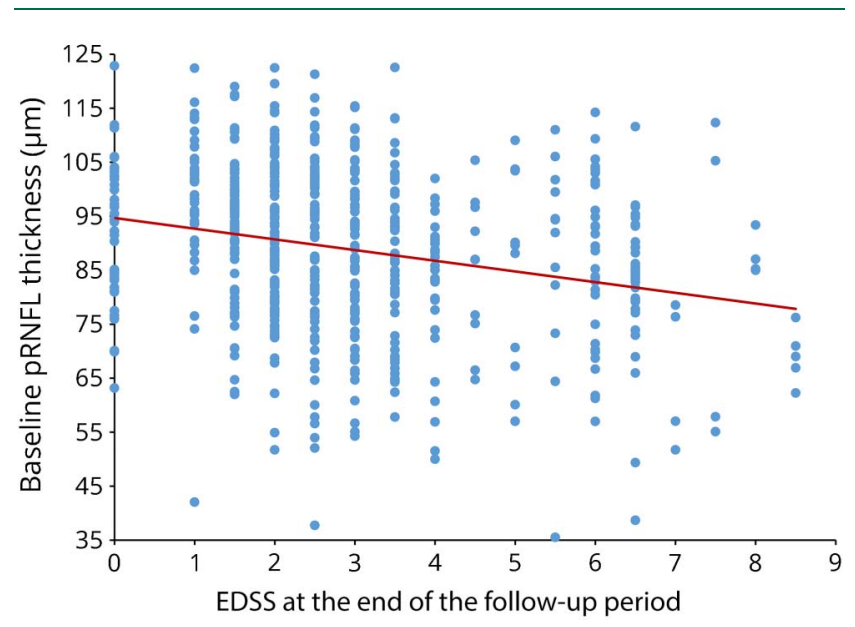

$\mathrm{RNFL}=$ retinal nerve fiber layer. individual level, SD-OCT is known to be more accurate. Stratus TD-OCT is no longer used in MS research because of the availability of more sophisticated OCT machines being able to quantify retinal measures with a much lower level of noise. ${ }^{8}$ Nevertheless, despite the effect on SDs, this noise does not affect the mean, and data from earlier iterations of the technology can be useful to indicate the association between retinal thinning and future disability.

\section{Author contributions}

C. Cordano: study concept and design, interpretation of data, and composition of the manuscript. B. Nourbakhsh: analysis and interpretation of data. M. Devereux and V. Damotte: acquisition of data and composition of the manuscript. D. Bennett: acquisition of data and supervision of the manuscript. S.L. Hauser and B.A.C. Cree: study supervision and composition of the manuscript. J.M. Gelfand: analysis and interpretation of data and composition of the manuscript. A.J. Green: study concept and design, analysis and interpretation of data, and composition of the manuscript.

\section{Study funding}

No targeted funding reported.

\section{Disclosure}

C. Cordano received research support from FISM and served as a consultant for Inception 5. B. Nourbakhsh received research support from Biogen, American Brain Foundation, National Multiple Sclerosis Society, and Patient-Centered Outcome Research Institute. M. Devereux reports no disclosures. V. Damotte received travel funding from ECTRIMS and ARSEP Foundation. D. Bennett reports no disclosures. S.L. Hauser served on the scientific advisory boards of Symbiotix, Annexon, Bionure, Molecular Stethoscope, Alector, and Neurona; received travel funding and speaker honoraria from F. Hoffmann La Roche; receives publishing royalties from McGraw-Hill Education; received writing support from F. Hoffmann La Roche; and received research support from the NIH, NMSS, and Conrad N. Hilton Foundation. B.A.C. Cree served on the scientific advisory board of Akili and consulted for AbbVie, Biogen, EMD Serono, GeNeuro, Novartis, and Sanofi Genzyme. J.M. Gelfand served on the DSMB for an NIA-funded study; is on the editorial board of Neurology: Neuroimmunology \& Neuroinflammation; received publishing royalties from DynaMed Plus; consulted for Biogen; received research support from MedDay and research support (to UCSF) from Genentech; is PI of an institutional clinician training award from the NMSS; received compensation for medical-legal consulting; his spouse is an associate editor of JAMA Neurology; received honoraria from UpToDate; and consulted for Zosano, Eli Lilly, Biohaven, and eNeura. A.J. Green served on the scientific advisory boards of MedImmune, Novartis, Inception 5 Sciences, Pipeline, and Bionure; served as an associate editor of JAMA Neurology and editorial board member of Neurology; holds a patent for remyelination molecules and pathways; received research support from Novartis, Inception Sciences, NINDS, NIA, 
NIH, NMSS, Sherak Foundation, and Hilton Foundation; holds stock or stock options in Inception 5, Pipeline, and Bionure; and served as an expert witness in Mylan Pharmaceuticals v Teva Pharmaceuticals. Full disclosure form information provided by the authors is available with the full text of this article at Neurology.org/NN.

\section{Publication history}

Received by Neurology: Neuroimmunology \& Neuroinflammation July 19, 2018. Accepted in final form November 8, 2018.

\section{References}

1. Arnold DL, Matthews PM, Francis G, Antel J. Proton magnetic resonance spectroscopy of human brain in vivo in the evaluation of multiple sclerosis: assessment of the load of disease. Magn Reson Med 1990;14:154-159.
2. Frohman EM, Costello F, Stüve O, et al. Modeling axonal degeneration within the anterior visual system: implications for demonstrating neuroprotection in multiple sclerosis. Arch Neurol 2008;65:26-35.

3. Martinez-Lapiscina EH, Arnow S, Wilson JA, et al. Retinal thickness measured with optical coherence tomography and risk of disability worsening in multiple sclerosis: a cohort study. Lancet Neurol 2016;15:574-584.

4. Leung CK, Chiu V, Weinreb RN, et al. Evaluation of retinal nerve fiber layer progression in glaucoma: a comparison between spectral-domain and time-domain optical coherence tomography. Ophthalmology 2011;118:1558-1562.

5. Polman $\mathrm{CH}$, Reingold SC, Edan G, et al. Diagnostic criteria for multiple sclerosis: 2005 revisions to the "McDonald Criteria". Ann Neurol 2005;58:840-846. Review.

6. Petzold A, de Boer JF, Schippling S, et al. Optical coherence tomography in multiple sclerosis: a systematic review and meta-analysis. Lancet Neurol 2010;9: 921-932.

7. Petzold A, Balcer LJ, Calabresi PA, et al. Retinal layer segmentation in multiple sclerosis: a systematic review and meta-analysis. Lancet Neurol 2017;16:797-812.

8. Warner CV, Syc SB, Stankiewicz AM, et al. The impact of utilizing different optical coherence tomography devices for clinical purposes and in multiple sclerosis trials. PLoS One 2011;6:e22947. 


\title{
Neurology \\ Neuroimmunology \& Neuroinflammation
}

\author{
pRNFL as a marker of disability worsening in the medium/long term in patients with \\ MS \\ Christian Cordano, Bardia Nourbakhsh, Michael Devereux, et al. \\ Neurol Neuroimmunol Neuroinflamm 2019;6; \\ DOI 10.1212/NXI.0000000000000533
}

This information is current as of December 21, 2018

Updated Information \&

Services

References

Subspecialty Collections

Permissions \& Licensing

Reprints including high resolution figures, can be found at:

http://nn.neurology.org/content/6/2/e533.full.html

This article cites 8 articles, 0 of which you can access for free at: http://nn.neurology.org/content/6/2/e533.full.html\#\#ref-list-1

This article, along with others on similar topics, appears in the following collection(s):

All Neuro-ophthalmology

http://nn.neurology.org//cgi/collection/all_neuroophthalmology

Multiple sclerosis

http://nn.neurology.org//cgi/collection/multiple_sclerosis

Optic nerve

http://nn.neurology.org//cgi/collection/optic_nerve

Information about reproducing this article in parts (figures,tables) or in its entirety can be found online at:

http://nn.neurology.org/misc/about.xhtml\#permissions

Information about ordering reprints can be found online:

http://nn.neurology.org/misc/addir.xhtml\#reprintsus

Neurol Neuroimmunol Neuroinflamm is an official journal of the American Academy of Neurology.

Published since April 2014, it is an open-access, online-only, continuous publication journal. Copyright

Copyright (C) 2018 The Author(s). Published by Wolters Kluwer Health, Inc. on behalf of the American

Academy of Neurology.. All rights reserved. Online ISSN: 2332-7812.

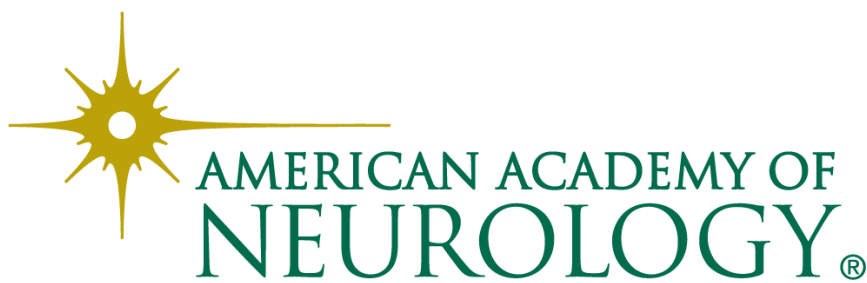

